\title{
PRODUTIVIDADE, ESTABILIDADE E ADAPTABILIDADE DE CULTIVARES DE AMENDOIM EM TRÊS NÍVEIS DE CONTROLE DE DOENÇAS FOLIARES ${ }^{1}$
}

\author{
IGNÁCIO JOSÉ DE GODOY², SÉRGIO ALMEIDA DE MORAES², WALTER JOSÉ SIQUEIRA² \\ JOSÉ CARLOS VILA NOVA ALVES PEREIRA ${ }^{3}$, ANTONIO LÚCIO DE MELLO MARTINS ${ }^{4}$ e EDSON MARTINS PAULO ${ }^{3}$
}

\begin{abstract}
RESUMO - O objetivo deste trabalho foi avaliar o desempenho produtivo, a estabilidade da produção e a adaptabilidade de três cultivares de amendoim em diversos ambientes típicos de cultivo e severidade das doenças foliares que podem ocorrer no Estado de São Paulo. Foram avaliadas as cultivares Tatu, Florunner e IAC-Caiapó sob três níveis de controle de doenças foliares, em experimentos onde as doenças predominantes foram a mancha-preta (Cercosporidium personatum) e a ferrugem (Puccinia arachidis). Os experimentos utilizaram delineamento em parcelas subdivididas com quatro repetições, em subparcelas de quatro linhas de $5 \mathrm{~m}$ de comprimento. As parcelas principais consistiram de controle químico com duas ou quatro pulverizações, e um tratamento sem controle das doenças. Estimaram-se, também, a estabilidade e adaptabilidade entre os ambientes, dentro de cada nível de controle das doenças. A cultivar Florunner mostrou as maiores respostas ao controle químico, em relação à produtividade e adaptabilidade aos ambientes onde as doenças foram bem controladas. As cultivares Tatu e IAC-Caiapó apresentaram comportamentos semelhantes em resposta ao controle das doenças e superaram a cultivar Florunner em produtividade, na qual a pressão das doenças foi maior. A cultivar IAC-Caiapó mostrou produtividade, maior que a da cultivar Tatu e desempenho produtivo mais estável (previsível) do que as outras cultivares, nos três níveis de controle das doenças.
\end{abstract}

Termos para indexação: Arachis hypogaea, cultivares, controle de doenças.

\section{YIELD, STABILITY AND ADAPTABILITY OF PEANUT CULTIVARS IN THREE LEVELS OF FOLIAR DISEASE CONTROL}

\begin{abstract}
Yield performance, stability and adaptability of three peanut cultivars were estimated over various environments typical of growing conditions and foliar disease severity that occur in the State of São Paulo, Brazil. Cultivars Tatu, Florunner and IAC-Caiapó were evaluated under three levels of disease control, in experiments where the prevailing diseases were the late leafspot (Cercosporidium personatum) and rust (Puccinia arachidis). Experiments used a splitplot design with four replications, in plots of four lines $5 \mathrm{~m}$ long. Main treatments consisted of chemical control of the diseases with two or four sprayings and a no-control treatment. Stability and adaptability over the environments were also estimated within each level of disease control. Cultivar Florunner showed the highest yields and responses to chemical control, as well as adaptability over environments where the diseases were well controlled. Responses of cultivars Tatu and IAC-Caiapó to disease control were similar, and both outyielded cultivar Florunner where disease pressure was higher. Cultivar IAC-Caiapó yielded higher than cultivar Tatu and showed yielding performance more stable (predictable) than the others in the three levels of disease control.
\end{abstract}

Index terms: Arachis hypogaea, cultivars, disease control.

\footnotetext{
${ }^{1}$ Aceito para publicação em 19 de outubro de 1998.

Trabalho parcialmente financiado pela FAPESP.

${ }^{2}$ Eng. Agr., Ph.D., Instituto Agronômico de Campinas (IAC), Caixa Postal 28, CEP 13001-970 Campinas, SP. Bolsista do CNPq. E-mail:ijgodoy@cec.iac.br

${ }^{3}$ Eng. Agr., IAC.

${ }^{4}$ Eng. Agr., M.Sc, IAC.
}

\section{INTRODUÇÃO}

O amendoim é um produto mundialmente comercializado e consumido in natura ou na forma de confeitos, além de ser fonte de óleo comestível largamente utilizado na culinária em 
muitos países. No Brasil, sua produção é da ordem de 100.000 toneladas/ano, atendendo à demanda interna, principalmente para a indústria de confeitaria. Essa produção está bastante concentrada no Estado de São Paulo, compreendendo uma área de cultivo de 60.000 hectares distribuídos em várias regiões agrícolas. Nessas regiões, a cultura garante a atividade de milhares de produtores com bom nível de tecnificação (São Paulo, 1997).

As condições de ambiente para a produção de amendoim em São Paulo são tipicamente tropicais, com índices pluviométricos que ultrapassam $1.000 \mathrm{~mm}$ durante o cultivo "das águas" (outubro a março). A alta umidade e temperatura durante esse período são propícias para as doenças foliares, exigindo um esquema de pulverizações com fungicidas para o seu controle (Pedro Júnior et al., 1994). Mesmo com a disponibilidade de fungicidas, o controle nem sempre é completo, principalmente quando ocorrem longos períodos de chuva constante, prejudicando as operações de campo e reduzindo a eficiência das aplicações.

No Brasil, a cultura comercial de larga escala utiliza, predominantemente, cultivares do tipo morfológico Valência, de ciclo curto (90 a 110 dias), hábito de crescimento ereto e moderado potencial produtivo. A cultivar Tatu, com essas características, é a mais plantada. Embora suscetível às doenças foliares, a sua precocidade pode ser considerada como um fator de adaptabilidade, propiciando um escape às doenças, principalmente quando a epidemia ocorre a partir dos 60 dias do ciclo (Moraes et al., 1994).

Com a abertura dos mercados internacionais, a produção brasileira de amendoim passou a exigir inovações tecnológicas que confiram maior competitividade em relação aos produtos externos. Entre as tecnologias, destaca-se a exploração de linhagens do tipo morfológico Virginia. Linhagens classificadas nesse tipo são as mais exploradas no melhoramento genético para obtenção de cultivares de alta capacidade produtiva em culturas mais tecnificadas (Sholar et al., 1995). Cultivares do tipo Virginia possuem hábito de crescimento rasteiro ou semi-rasteiro, que possibilita a mecanização total da colheita (reduzindo o alto custo da mão-de-obra) e o ciclo longo, componente associado ao maior potencial produtivo.

Entre as cultivares mais conhecidas do tipo Virginia, a cultivar Florunner em cultivo desde a década de 1970, é bastante difundida em diversas regiões produtoras dos Estados Unidos, constituindo-se, ainda hoje, em padrão de produtividade e adaptabilidade em diversos ambientes (Norden et al., 1982; Sholar et al., 1995). Na Argentina, atualmente o terceiro exportador mundial de amendoim, a introdução dessa cultivar, na década de 1980, foi bem-sucedida, substituindo os tradicionais amendoins do tipo Valência e elevando consideravelmente o nível da produtividade na região (Godoy \& Giandana, 1992). Uma das razões para esse êxito é a adaptação da cultivar Florunner às condições semi-áridas locais, onde essa cultivar, suscetível às doenças foliares, pode ser cultivada com um número mínimo de pulverizações (Freitas et al., 1995).

A introdução de novas cultivares em uma região ou sistema de produção deve considerar como prioridade a sua estabilidade e adaptabilidade em diversas condições de cultivo. Em amendoim, conforme revisto por Knauft \& Wynne (1995), a maioria dos estudos envolvendo avaliações de genótipos em diversos ambientes indica interações significativas. Estudos de estabilidade (Anderson et al., 1989) mostram diferenças entre genótipos quando se compara o desempenho produtivo entre ambientes favoráveis e desfavoráveis

Em São Paulo, a utilização de cultivares de ciclo longo (125 a 140 dias), mantidos os padrões atuais de cultivo, pode representar aumento de riscos para o sucesso da cultura, principalmente tratando-se de genótipos suscetíveis às doenças foliares. A cultivar IAC-Caiapó, selecionada de cruzamento envolvendo linhagem do tipo Virginia (Godoy et al., 1996), assemelha-se à cultivar Florunner quanto ao ciclo e hábito de crescimento, apresentando, como vantagens, a maior produtividade em relação à cultivar Tatu, padrão local, e a resistência parcial e múltipla, às doenças foliares, mancha-preta (Cercosporidium personatum), mancha-castanha (Cercospora arachidicola), verrugose (Sphaceloma arachidis), mancha-barrenta (Phoma arachidicola) e ferrugem (Puccinia arachidis). 
Levando-se em consideração as características básicas descritas, com relação ao potencial produtivo, suscetibilidade ou resistência parcial às doenças e duração de ciclo, este trabalho objetivou comparar o desempenho produtivo, a estabilidade da produção e a adaptabilidade das três cultivares em diversos ambientes, típicos das condições de cultivo e severidade das doenças que podem ocorrer no Estado de São Paulo.

\section{MATERIAL E MÉTODOS}

As produtividades, em $\mathrm{kg} / \mathrm{h}$ a de vagens, das cultivares Tatu, Florunner e IAC-Caiapó, foram avaliadas em nove experimentos, conduzidos na época "das águas" nas Estações Experimentais do Instituto Agronômico em Ribeirão Preto (em 1990/91, 91/92, 92/93 e 93/94), Pindorama (em 1990/91, 91/92, 92/93 e 93/94) e Adamantina (1991/92), localizadas em regiões produtoras de amendoim.

Em cada experimento foi utilizado um delineamento em parcelas subdivididas em blocos ao acaso com quatro repetições, com subparcela de quatro linhas de $5 \mathrm{~m}$ de comprimento, considerando-se as duas linhas laterais como bordaduras. $\mathrm{O}$ espaçamento entre linhas foi de $0,7 \mathrm{~m}$ para as cultivares Florunner e IAC-Caiapó, rasteiras, e de 0,6 m para a cultivar Tatu, de porte ereto. O plantio foi feito em terreno previamente calcareado, efetuando-se, em todos os experimentos, uma adubação com $250 \mathrm{~kg} / \mathrm{ha}$ de NPK na fórmula de 4-14-8.

Os tratamentos estudados consistiram das três cultivares em três níveis de controle químico das doenças, a saber: 1. ausência de controle; 2 . controle parcial: duas pulverizações durante o ciclo (em Ribeirão Preto, 1993/94, houve só uma pulverização, porém com resultado semelhante a experimentos contíguos com duas pulverizações); 3 . controle completo: quatro pulverizações durante o ciclo. Em Ribeirão Preto, 1990/91, o experimento não teve o tratamento intermediário, com duas pulverizações. Na cultivar Tatu, precoce, a primeira pulverização foi feita aos 42-45 dias do plantio, enquanto nas cultivares Florunner e IAC-Caiapó, de ciclo longo, as pulverizações iniciaram-se aos 55-60 dias do plantio. Para as três cultivares, as pulverizações (onde houve mais de uma) os intervalos foram de 15 dias. Todas as pulverizações foram feitas com Clorotalonil, na dose de 1,5 litro do princípio ativo/ha, na formulação concentrado emulsionável.
A escolha do número de pulverizações $(0,2$ ou 4$)$ para compor os tratamentos objetivou produzir, nos experimentos, condições diversas de controle químico e, portanto, de severidade das doenças, além de avaliar o efeito do número de pulverizações em si.

Além das variações resultantes dos tratamentos com diversas intensidades de controle químico, registraram-se, entre os nove experimentos, variações com relação à presença do patógeno e à severidade da doença. Em oito dos nove experimentos, a doença foliar predominante foi a mancha-preta, causada por Cercosporidium personatum. As maiores severidades de mancha-preta ocorreram em Ribeirão Preto, em 90/91 e 92/93 e em Pindorama em 92/93. Os experimentos de Ribeirão Preto, Pindorama e Adamantina, em 91/92, apresentaram as mais baixas severidades da doença. Em 93/94, a severidade da manchapreta foi moderada, tanto em Ribeirão Preto como em Pindorama. No experimento de Pindorama, em 90/91, verificou-se uma alta e incomum severidade de ferrugem (Puccinia arachidis) e um nível muito baixo de sintomas de C. personatum.

A colheita foi feita manualmente, em todos os experimentos. A determinação do melhor ponto para a arranca das plantas objetivou a obtenção da máxima produção de vagens em cada tratamento. A cultivar Tatu foi colhida entre 97 e 110 dias, dependendo do experimento. As cultivares Florunner e IAC-Caiapó foram colhidas entre $125 \mathrm{e}$ 140 dias. Em alguns casos, foi necessário adiantar a arranca em alguns dias, visando minimizar as perdas de colheita, em face do avançado estado de desfolha e deterioração das plantas. Assim, em Pindorama e Ribeirão Preto, em 92/93, as parcelas não pulverizadas da cultivar Florunner foram colhidas aos 115 e 120 dias, respectivamente.

Quanto às análises de estabilidade, optou-se por desdobrar os experimentos individuais, criando-se grupos de experimentos correspondentes a três níveis de controle das doenças: o primeiro, consistiu das comparações entre as cultivares em nove experimentos (ambientes), no tratamento sem controle químico das doenças (grupo S); o segundo, em oito ambientes, no tratamento correspondente ao controle parcial (grupo P); e o terceiro, em nove ambientes, no controle completo das doenças (grupo C).

A estabilidade e adaptabilidade foram estudadas segundo método descrito por Eberhart \& Russell (1966), utilizando as médias das cultivares em cada ambiente e o valor do quadrado médio residual da análise conjunta em cada grupo de ambientes. Esse método leva em consideração, além das médias dos genótipos, a resposta (linear) ao longo de todos os ambientes, e os desvios da reta de regressão, obtida com as médias em escala crescente, dos ambientes mais desfavoráveis aos mais favoráveis. 


\section{RESULTADOS E DISCUSSÃO}

A Tabela 1 mostra as produtividades de amendoim em vagens, obtidas das três cultivares estudadas em três níveis de controle das doenças.

Nas três cultivares houve resposta progressiva ao controle químico, tanto da mancha-preta (em oito dos experimentos) como da ferrugem (em Pindorama-90/91), independentemente do nível de produtividade geral do experimento.

TABELA 1. Produtividade de três cultivares de amendoim em três níveis de controle químico de doenças foliares em nove experimentos no Estado de São Paulo. Médias de 4 repetições 1 .

\begin{tabular}{|c|c|c|c|c|}
\hline \multirow[t]{2}{*}{ Experimento } & \multirow[t]{2}{*}{ Cultivar } & \multicolumn{3}{|c|}{ Controle de doenças ${ }^{2}$} \\
\hline & & $S$ & $\mathrm{P}$ & $\mathrm{C}$ \\
\hline \multirow{4}{*}{$\begin{array}{l}\text { Pindorama } \\
90 / 91\end{array}$} & & \multicolumn{3}{|c|}{--------- kg/ha ----------- } \\
\hline & Tatu & $1938 \mathrm{aC}$ & $2283 \mathrm{aB}$ & $2852 \mathrm{aA}$ \\
\hline & Florunner & $479 b C$ & $1281 \mathrm{bB}$ & $3034 \mathrm{aA}$ \\
\hline & IAC-Caiapó & $2060 \mathrm{aC}$ & $2591 \mathrm{aB}$ & $3147 \mathrm{aA}$ \\
\hline \multirow{3}{*}{$\begin{array}{l}\text { Ribeirão Preto } \\
90 / 91\end{array}$} & Tatu & $4258 \mathrm{aA}$ & - & $4831 \mathrm{bA}$ \\
\hline & Florunner & $3429 b B$ & - & $6452 \mathrm{aA}$ \\
\hline & IAC-Caiapó & $4089 \mathrm{abB}$ & - & $6135 \mathrm{aA}$ \\
\hline \multirow{3}{*}{$\begin{array}{l}\text { Pindorama } \\
91 / 92\end{array}$} & Tatu & $3878 \mathrm{aA}$ & $4224 \mathrm{bA}$ & $4251 \mathrm{bA}$ \\
\hline & Florunner & $3724 \mathrm{aC}$ & $5017 \mathrm{aB}$ & $5839 \mathrm{aA}$ \\
\hline & IAC-Caiapó & $3672 \mathrm{aB}$ & $4737 \mathrm{abA}$ & $5348 \mathrm{aA}$ \\
\hline \multirow{3}{*}{$\begin{array}{l}\text { Ribeirão Preto } \\
91 / 92\end{array}$} & Tatu & $4247 \mathrm{aA}$ & $4624 \mathrm{bA}$ & $4848 \mathrm{bA}$ \\
\hline & Florunner & $4665 \mathrm{aC}$ & $5579 \mathrm{aB}$ & $6349 \mathrm{aA}$ \\
\hline & IAC-Caiapó & $4240 \mathrm{aB}$ & $4466 \mathrm{bAB}$ & $4922 \mathrm{bA}$ \\
\hline \multirow{3}{*}{$\begin{array}{l}\text { Adamantina } \\
91 / 92\end{array}$} & Tatu & $3860 \mathrm{bB}$ & $4044 \mathrm{cB}$ & $4888 \mathrm{bA}$ \\
\hline & Florunner & $4317 \mathrm{bB}$ & $4720 \mathrm{bB}$ & $5971 \mathrm{aA}$ \\
\hline & IAC-Caiapó & $4983 \mathrm{aB}$ & $5447 \mathrm{aAB}$ & $5827 \mathrm{aA}$ \\
\hline \multirow{3}{*}{$\begin{array}{l}\text { Pindorama } \\
92 / 93\end{array}$} & Tatu & $2915 \mathrm{aA}$ & $2950 \mathrm{bA}$ & $3438 \mathrm{cA}$ \\
\hline & Florunner & $1425 \mathrm{bB}$ & $2104 c B$ & $6591 \mathrm{aA}$ \\
\hline & IAC-Caiapó & $3615 \mathrm{aB}$ & $3833 \mathrm{aB}$ & $5280 \mathrm{bA}$ \\
\hline \multirow{3}{*}{$\begin{array}{l}\text { Ribeirão Preto } \\
92 / 93\end{array}$} & Tatu & $1508 \mathrm{bA}$ & $1902 \mathrm{bA}$ & $2177 \mathrm{cA}$ \\
\hline & Florunner & $2515 \mathrm{aC}$ & $3384 \mathrm{aB}$ & $5464 \mathrm{aA}$ \\
\hline & IAC-Caiapó & $2676 \mathrm{aB}$ & $3517 \mathrm{aA}$ & $3626 \mathrm{bA}$ \\
\hline \multirow{3}{*}{$\begin{array}{l}\text { Pindorama } \\
93 / 94\end{array}$} & Tatu & $3248 \mathrm{aA}$ & $3842 \mathrm{aA}$ & $4043 \mathrm{aA}$ \\
\hline & Florunner & $1589 \mathrm{bC}$ & $2863 \mathrm{bB}$ & $4139 \mathrm{aA}$ \\
\hline & IAC-Caiapó & $2388 \mathrm{abB}$ & $4278 \mathrm{aA}$ & $4590 \mathrm{aA}$ \\
\hline \multirow{3}{*}{$\begin{array}{l}\text { Ribeirão Preto } \\
93 / 94\end{array}$} & Tatu & $3584 \mathrm{aB}$ & $3728 \mathrm{bAB}$ & $4257 \mathrm{bA}$ \\
\hline & Florunner & $3332 \mathrm{aC}$ & $4332 \mathrm{aB}$ & $5753 \mathrm{aA}$ \\
\hline & IAC-Caiapó & $3864 \mathrm{aC}$ & $4478 \mathrm{aB}$ & $5837 \mathrm{aA}$ \\
\hline \multirow[t]{3}{*}{ Médias } & Tatu & $3271 \mathrm{bB}$ & $3475 \mathrm{bB}$ & $3932 \mathrm{cA}$ \\
\hline & Florunner & $2831 \mathrm{cC}$ & $3660 \mathrm{bB}$ & $5510 \mathrm{aA}$ \\
\hline & IAC-Caiapó & $3510 \mathrm{aC}$ & $4168 \mathrm{aB}$ & $4968 \mathrm{bA}$ \\
\hline
\end{tabular}

Os testes de significância das médias das cultivares Florunner e IAC-Caiapó acusaram diferenças significativas (a 5\%) entre os três níveis de controle das doenças, na maioria dos experimentos.

Em relação à cultivar Tatu, embora as médias tenham sempre aumentado do tratamento "sem controle" para o de "controle completo", as diferenças não foram significativas em seis dos nove experimentos.

Entre as cultivares Florunner e IAC-Caiapó, a primeira foi a que apresentou as maiores diferenças em produtividade, em resposta ao controle químico. Em alguns experimentos, principalmente nos tratamentos em que as doenças não foram controladas, a drástica queda de produtividade da cultivar Florunner em relação aos tratamentos pulverizados foi, sem dúvida, causada pela suscetibilidade da cultivar às doenças. Em alguns casos, principalmente em Pindorama-90/91, a baixa produção da cultivar nas parcelas não pulverizadas foi, em parte, resultante das perdas ocorridas durante a arranca manual das plantas, em face do estado de deterioração da parte aérea.

Em qualquer das três cultivares, as variações nas produtividades entre experimentos não podem ser atribuídas somente à presença ou severidade das doenças. Isso pode ser evidenciado pelo seu comportamento nas condições em que as doenças foram bem controladas (tratamentos C), i.e., mesmo sem o efeito das doenças, as produtividades apresentaram variações, que podem ser atribuídas a outros fatores do ambiente que normalmente variam entre locais ou anos de cultivo.

As médias de produtividade dentro de cada nível de controle químico, nos diversos experimentos, foram variáveis entre as cultivares, nos três níveis de controle das doenças (Tabela 1). A cultivar IAC-Caiapó apresentou o melhor desempenho produtivo na média dos nove experimentos, na ausência de controle $(3.510 \mathrm{~kg} / \mathrm{ha}$, no tratamento $\mathrm{S})$ e no controle intermediário das doenças $(4.169 \mathrm{~kg} / \mathrm{ha}$, no tratamento P). Na ausência de controle, a produtividade da cultivar Tatu foi significativamente superior à da cultivar Florunner, não diferindo desta quando o controle das doenças foi parcial (tratamento P). 
A cultivar Florunner expressou o seu alto potencial produtivo quando se compararam as cultivares no tratamento $\mathrm{C}$, nas quais as doenças foram bem controladas. A cultivar americana atingiu a média de $5.510 \mathrm{~kg} / \mathrm{ha}$, entre os nove experimentos, contra 4.968 e $3.932 \mathrm{~kg} / \mathrm{ha}$ das cultivares IAC-Caiapó e Tatu, respectivamente (diferenças significativas a $5 \%$ ).

As comparações das produtividades das três cultivares nos três níveis de controle das doenças mostram evidentes diferenças de desempenho produtivo, associadas ao fator doença e às características de cada cultivar. A cultivar Florunner, de alta capacidade produtiva, porém suscetível tanto à mancha-preta como à ferrugem, foi superada pela cultivar IAC-Caiapó, de capacidade produtiva média a alta, porém parcialmente resistente, nos experimentos onde o fator doença foi predominante. A cultivar Tatu, de moderada produtividade, apresentou desempenho mais próximo da cultivar Florunner, em que a pressão das doenças foi mais limitante em relação às produções (tratamentos $\mathrm{S}$ e P). Essa vantagem pode ser explicada pela precocidade da cultivar, que propicia um escape à doença principalmente em condições de cultivo em que o processo epidemiológico ocorre com certo atraso durante o ciclo (Moraes et al., 1994).

Do ponto de vista agronômico, e levando-se em consideração somente os aspectos potencial produtivo, duração do ciclo e desempenho em função do controle químico das doenças, as diferenças observadas entre as cultivares estudadas sugerem a possibilidade de opção do produtor pelas vantagens de uma ou de outra, dependendo do sistema de produção, das condições agroclimáticas e do custo do controle químico.

Entretanto, como as médias das três cultivares foram bastante variáveis entre os diversos experimentos, na presença ou não das doenças, é importante avaliar, também, o seu desempenho quanto à estabilidade da produção e adaptabilidade nos ambientes aqui considerados.

O resumo das análises de variância conjunta dentro de cada grupo de ambientes, criados de acordo com o nível de controle das doenças, encontra-se na Tabela 2. Nos três grupos, os valores de F estimados em relação aos ambientes, cultivares e
TABELA 2. Resumo das análises de variância conjunta relativas ao caráter produtividade, em $\mathrm{kg} / \mathrm{ha}$ de vagens, das cultivares de amendoim, em três grupos de experimentos (ambientes).

\begin{tabular}{|c|c|c|c|c|c|}
\hline \multicolumn{2}{|c|}{ Ambientes } & \multirow{2}{*}{$\begin{array}{c}\text { Causas de } \\
\text { variação }\end{array}$} & \multirow[t]{2}{*}{ G.L. } & \multirow{2}{*}{$\begin{array}{l}\text { Quadrados } \\
\text { médios }\end{array}$} & \multirow{2}{*}{$\begin{array}{c}\text { Valores } \\
\text { F }\end{array}$} \\
\hline Grupo $^{1}$ & $\overline{\mathrm{CV}(\%)^{2}}$ & & & & \\
\hline \multirow[t]{4}{*}{ S } & 11,5 & Ambientes (A) & 8 & $12.870 .772,63$ & $94,56^{* *}$ \\
\hline & & Cultivares (C) & 2 & $4.274 .235,84$ & $31,40 * *$ \\
\hline & & $\mathrm{A} \times \mathrm{C}$ & 16 & $1.348 .736,98$ & $9,91 * *$ \\
\hline & & Resíduo & 54 & $136.105,07$ & \\
\hline \multirow[t]{4}{*}{$\mathrm{P}$} & 13,2 & Ambientes (A) & 7 & $12.777 .825,71$ & $51,91 * *$ \\
\hline & & Cultivares (C) & 2 & $4.129 .587,88$ & $16,78 * *$ \\
\hline & & $\mathrm{A} \times \mathrm{C}$ & 14 & $1.565 .020,94$ & $6,36 * *$ \\
\hline & & Resíduo & 48 & $246.136,55$ & \\
\hline \multirow[t]{4}{*}{$\mathrm{C}$} & 10,8 & Ambientes (A) & 8 & $10.541 .170,36$ & $38,98 * *$ \\
\hline & & Cultivares (C) & 2 & $23.166 .656,79$ & $85,98 * *$ \\
\hline & & $\mathrm{A} \times \mathrm{C}$ & 16 & $1.423 .335,11$ & $5,26^{* *}$ \\
\hline & & Resíduo & 54 & $270.394,58$ & \\
\hline
\end{tabular}

$1 \mathrm{~S}$ : sem controle químico das doenças foliares; P: com controle parcial C: com controle completo.

${ }^{2}$ Coeficiente de variação da respectiva análise conjunta.

interações ambientes x cultivares foram significativos.

A Tabela 3 e a Fig. 1 apresentam os resultados das análises de estabilidade e adaptabilidade das cultivares.

As cultivares Tatu e IAC-Caiapó apresentaram valores de $\beta_{1}$ menores que a cultivar Florunner, nos três grupos de ambientes. Essas diferenças foram mais pronunciadas nos ambientes $\mathrm{S}$ e $\mathrm{P}$ (onde ocorrem as doenças).

Em $\mathrm{S}$, os valores de $\beta_{1}$ foram significativamente maiores que 1 na cultivar Florunner e menores que 1 (a 5\%) nas outras duas cultivares. O mesmo comportamento ocorreu nos ambientes $\mathrm{P}$, embora na cultivar Tatu o teste $t$ não tenha acusado significância. Em C (na ausência das doenças), os valores de $\beta_{1}$ não foram significativamente diferentes de 1 , nas três cultivares, embora as tendências tenhamse mantido nas cultivares Tatu $\left(\beta_{1}<1\right)$ e Florunner $\left(\beta_{1}>1\right)$.

Os valores de $\beta_{1}$ superiores a 1 , observados na cultivar Florunner, são indicativos de adaptabilidade específica a ambientes favoráveis. Entretanto, 
TABELA 3. Produtividades médias e parâmetros de estabilidade de cultivares de amendoim em três grupos de ambientes relativos ao nível de controle químico das doenças foliares. Estimativas segundo Eberhart \& Russell (1966).

\begin{tabular}{|c|c|c|c|c|c|}
\hline \multirow{2}{*}{$\begin{array}{l}\text { Grupos de } \\
\text { ambientes }^{1}\end{array}$} & \multirow[t]{2}{*}{ Cultivares } & \multirow{2}{*}{$\begin{array}{c}\text { Produtividades } \\
\text { médias }\end{array}$} & \multicolumn{3}{|c|}{ Parâmetros de estabilidade } \\
\hline & & & $\begin{array}{c}\text { Coeficientes de } \\
\text { regressão linear } \\
\left(\beta_{1}\right) \\
\end{array}$ & $\begin{array}{c}\text { Variâncias dos } \\
\text { desvios de } \\
\text { regressão } \\
\end{array}$ & $\begin{array}{c}\text { Coeficientes } \\
\text { de } \\
\text { determinação }\left(\mathrm{R}^{2}\right)\end{array}$ \\
\hline \multirow{4}{*}{ S } & & $(\mathrm{kg} / \mathrm{ha})$ & & & $(\%)$ \\
\hline & Tatu & 3271 & $0,842 *$ & $203.779,2 * * *$ & 78,5 \\
\hline & Florunner & 2831 & $1,298 * *$ & $203.892,1 * * *$ & 89,7 \\
\hline & IAC-Caiapó & 3510 & $0,859 *$ & $97.150,4^{* * *}$ & 87,3 \\
\hline \multirow[t]{3}{*}{$P$} & Tatu & 3475 & $0,854^{\mathrm{ns}}$ & $158.271,2 * * *$ & 80,5 \\
\hline & Florunner & 3660 & $1,377 * *$ & $230.752,5 * * *$ & 89,0 \\
\hline & IAC-Caiapó & 4168 & $0,768^{*}$ & $69.146,5^{\mathrm{ns}}$ & 84,9 \\
\hline \multirow[t]{3}{*}{$\mathrm{C}$} & Tatu & 3932 & $0,867^{\text {ns }}$ & $215.434,7 * * *$ & 72,7 \\
\hline & Florunner & 5510 & $1,089^{\text {ns }}$ & $335.420,8 * * *$ & 74,7 \\
\hline & IAC-Caiapó & 4968 & $1,044^{\mathrm{ns}}$ & $32.234,4^{\mathrm{ns}}$ & 91,6 \\
\hline
\end{tabular}

${ }^{1} \mathrm{~S}$ : sem controle químico das doenças foliares; P: controle parcial; C: controle completo.

* $\beta_{1}$ significativamente diferente de 1 pelo teste $t$ a $5 \%$ de probabilidade.

** $\beta_{1}$ significativamente diferente de 1 pelo teste t a $1 \%$ de probabilidade.

*** Variância significativa pelo teste $\mathrm{F}$ a $1 \%$ de probabilidade.

esse comportamento foi mais evidente onde ocorreu a pressão das doenças foliares sobre a produtividade (ambientes $\mathrm{S}$ e $\mathrm{P}$ ). Nesses ambientes, os valores de $\beta_{1}<1$ observados nas cultivares Tatu e IAC-Caiapó indicaram adaptabilidade específica a ambientes desfavoráveis.

Em $\mathrm{C}$, em que as doenças foram controladas, os coeficientes $\beta_{1}$ aproximaram-se de 1, principalmente nas cultivares Florunner e IAC-Caiapó. Segundo Eberhart \& Russell (1966), conforme descrito em Cruz \& Regazzi (1994), genótipos cujo $\beta_{1}$ é próximo de 1 demonstram adaptabilidade geral ou ampla. Portanto, pode-se interpretar que tanto 'Florunner' como 'IAC-Caiapó' possuem esses atributos, quando os fatores preponderantes relativos às variações entre os ambientes não são as doenças foliares. Nessas condições, a cultivar Florunner é a mais produtiva, e a sua reconhecida adaptabilidade (Norden et al., 1982; Sholar et al., 1995) pode então ser explicada. No caso da cultivar Tatu, embora não significativo nos ambientes $\mathrm{P}$ e $C$, o valor de $\beta_{1}$, sempre abaixo de 1 , sugere a menor responsividade da cultivar, entre as três es- tudadas, tanto na ausência como na presença de doenças.

Entre as cultivares Florunner e IAC-Caiapó, as retas de regressão (Fig. 1) apresentaram tendências bastante próximas nos ambientes $\mathrm{C}$ (doenças controladas), o que confirma o seu comportamento semelhante em termos de resposta a outros fatores do ambiente que não as doenças. Por outro lado, a similaridade das respostas das cultivares IAC-Caiapó e Tatu nos ambientes S e P mostra que o nível de resistência (parcial) da primeira à mancha-preta e ferrugem foi suficiente para compensar a desvantagem do ciclo mais longo em ambientes sob alta pressão das doenças.

As variâncias dos desvios das regressões (Tabela 3 ) foram maiores na cultivar Florunner, embora todos os valores, exceto na IAC-Caiapó nos ambientes $\mathrm{P}$ e $\mathrm{C}$, tenham sido altamente significativos (variâncias significativamente diferentes de zero). A cultivar Florunner apresentou variâncias altas e significativas (com o valor de ajuste da reta de regressão, $\mathrm{R}^{2}=74,7 \%$ ) mesmo nos ambientes $\mathrm{C}$ (doenças controladas). A cultivar Tatu apresentou 

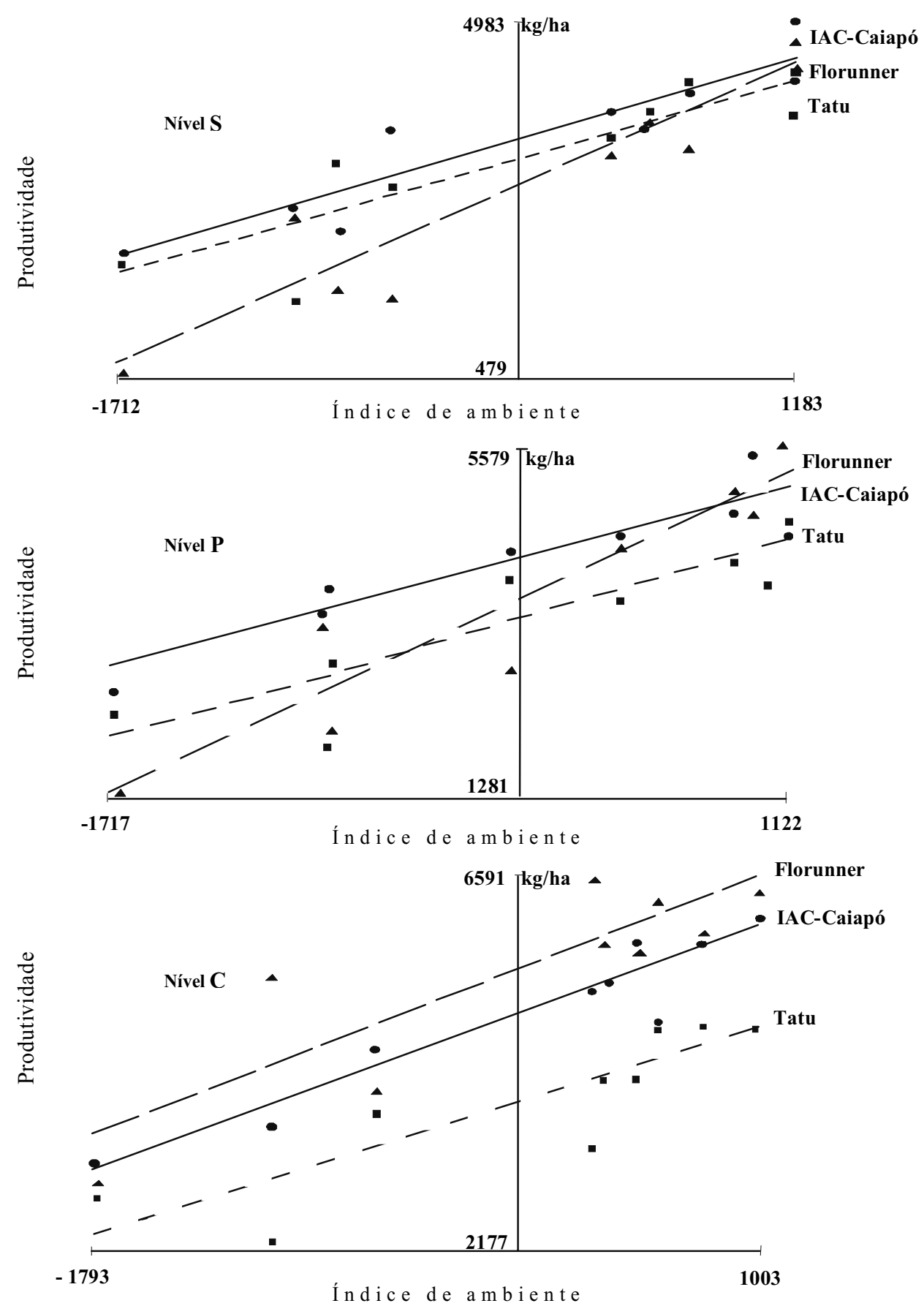

FIG. 1. Estabilidade e adaptabilidade, segundo Eberhart \& Russell (1996), em relação ao caráter produtividade de cultivares de amendoim em três níveis de controle das doenças foliares (S: sem controle químico; $\mathrm{P}$ : controle parcial; $\mathrm{C}$ : controle completo). Legenda de cultivares: Tatu (ם), Florunner ( $\Delta$ ), IAC-Caiapó ( $\bullet$ ). 
variâncias de magnitudes próximas, porém menores que as da cultivar Florunner, principalmente nos ambientes P. Seus valores de $\mathrm{R}^{2}$ variaram de $72,7 \%$ a $80,5 \%$, i.e., os menores entre as três cultivares, nos três grupos de ambientes. A cultivar IAC-Caiapó apresentou as menores variâncias entre as três cultivares nos três grupos de ambientes, com valores de $\mathrm{R}^{2}$ variando de $84,9 \%$ (em P) a 91,6\% (em C).

Menores desvios são indicativos de maior estabilidade (ou previsibilidade), uma vez que as variações em produtividade são melhor relacionadas às variações dos ambientes. Nesse sentido, pode-se considerar que a cultivar IAC-Caiapó exibiu comportamento mais previsível do que as demais, tanto em condições de pouco ou nenhum controle das doenças como na ausência de pressão das doenças sobre a produtividade. A cultivar Florunner foi a que apresentou desempenho produtivo menos previsível, mesmo quando o fator doença não foi preponderante nas variações entre os ambientes. Embora ela tenha mostrado satisfatória adaptabilidade na ausência de doenças, a menor previsibilidade apresentada nessas condições em relação às outras duas cultivares sugere que outros fatores do ambiente, responsáveis por essas variações, devem ser investigados.

Assim, pode-se sugerir que a introdução ou seleção de genótipos do tipo Virginia com as características da cultivar Florunner só é recomendável em condições ótimas de controle das manchasfoliares. Mesmo assim, a estabilidade da cultivar às variações do ambiente nas regiões produtoras de São Paulo precisa ser melhor conhecida.

Nos atuais padrões de cultivo (sem elevação de custos de controle químico), a resistência múltipla e parcial da cultivar IAC-Caiapó é, no mínimo, suficiente para permitir uma resposta similar à cultivar precoce, de desempenho já conhecido na região produtora. Além de mostrar-se satisfatoriamente adaptável (responsiva) a outros fatores do ambiente não relacionados com as doenças foliares, a cultivar IAC-Caiapó possui maior potencial produtivo do que a cultivar Tatu, com a vantagem adicional, em relação às outras duas cultivares, de exibir respostas mais previsíveis às variações do ambiente, com ou sem a pressão das doenças.

\section{CONCLUSÕES}

1. As cultivares de amendoim Florunner e IAC-Caiapó, apresentam desempenho produtivo superior à cultivar Tatu, cultivar precoce largamente disseminada nas regiões produtoras de São Paulo, principalmente quando as doenças foliares são parcial ou totalmente controladas.

2. Na presença de doenças, a cultivar Florunner mostra adaptabilidade específica aos ambientes mais favoráveis; quando as doenças são eficientemente controladas, sua adaptabilidade é mais ampla, e o seu desempenho produtivo médio é superior ao das outras duas cultivares.

3. A cultivar IAC-Caiapó, de ciclo longo e parcialmente resistente, apresenta respostas às variações do ambiente similares às da cultivar Tatu, precoce e suscetível, com a vantagem de exibir maior produtividade do que esta, com ou sem a presença de doenças.

4. A cultivar Florunner apresenta produtividade menos previsível que a da cultivar IAC-Caiapó, mesmo quando as doenças são controladas, sugerindo que outros fatores do ambiente também podem contribuir para as variações em produtividade.

\section{REFERÊNCIAS}

ANDERSON,W.F.; MOZINGO, R.W.; WYNNE, J.C. Comparison of stability statistics as criteria for cultivar development in peanut. Peanut Science, Raleigh, v.16, n.1, p.21-25,1989.

CRUZ, C.D.; REGAZZI, A.J. Modelos biométricos aplicados ao melhoramento genético. Viçosa, MG: UFV, 1994. 390p.

EBERHART, S.A.; RUSSELL, W.A. Stability parameters for comparing varieties. Crop Science, Madison, v.6, p.36-40, 1966 .

FREITAS, S.M.; GODOY, I.J. de; VIEIRA, R.D. Aspectos comparativos da produção e comercialização de amendoim nos países do Mercosul. Informações Econômicas, São Paulo, v.25, n.1, p.49-56, 1995.

GODOY, I.J. de; GIANDANA, E.H. Groundnut production and research in South America. In: NIGAN, S.N. (Ed.). Groundnut - a global perspective: Proceedings of an International Workshop. Patancheru, India: ICRISAT Center, 1992. p.77-85. 
GODOY, I.J. de; MORAES, S.A.; TURATTI, J.M.; PEREIRA, J.C.V.N.A.; MARTINS, A.L.M.; PAULO, E.M. IAC-CAIAPÓ: novo cultivar de amendoim. Campinas: Instituto Agronômico, 1996. 4p. Folder.

KNAUFT, D.A.; WYNNE, J.C. Peanut breeding and genetics. Advances in Agronomy, New York, v.55, p.393-445, 1995 .

MORAES, S.A.; GODOY, I.J. de; MARTINS, A.L.M.; PEREIRA, J.C.V.N.A.; PEDRO JÚNIOR, M.J Epidemiologia da mancha-preta (Cercosporidium personatum) em amendoim: resistência, controle químico e progresso da doença. Fitopatologia Brasileira, Brasília, v.19, n.2, p.532-540, 1994.

NORDEN, A.J.; SMITH, O.D.; GORBET, W. Breeding of the cultivated peanut. In: PATTEE, H.E.; YOUNG, C.T. (Eds.). Peanut science and technology.
Yoakum, Texas: American Peanut Research and Education Society, 1982. Ch.4, p.95-122.

PEDRO JÚNIOR, M.J.; MORAES, S.A.; GODOY, I.J. de. Agrometeorological forecasting method for Cercospora leafspot in peanuts. Fitopatologia Brasileira, Brasília, v.19, n.1, p.69-73, 1994.

SÃO PAULO. Secretaria da Agricultura e Abastecimento. Coordenadoria de Assistência Técnica Integral. Amendoim - produção em São Paulo e implicações no Mercosul. Campinas, 1997. 9p. (Documento Técnico, n.105).

SHOLAR, J.R.; MOZINGO, R.W.; BEASLEY JUNIOR, J.P. Peanut cultural practices. In: PATTEE, H.E; STALJER, T. (Eds.). Advances in peanut science. Stillwater, Oklahoma: American Peanut Research and Education Society, 1995. Ch.10, p.354-382. 